\title{
TSpace Research Repository tspace.library.utoronto.ca \\ The Company They Keep: Drinking Group Attitudes and Male Bar Aggression
}

\author{
Tara M. Dumas, Kathryn Graham, and Samantha Wells
}

Version Post-Print/Accepted Manuscript

Citation Dumas, T.M., Graham, K., \& Wells, S. The company they keep:

(published version) Drinking group attitudes and male bar aggression. Journal of Studies on Alcohol and Drugs, 76, 447-451, 2015. DOI: 10.15288/jsad.2015.76.447

Publisher's Statement The final publication is available at Journal of Studies on Alcohol and Drugs via https://dx.doi.org/10.15288/jsad.2015.76.447.

Always cite the published version, so the author(s) will receive recognition through services that track citation counts, e.g. Scopus. If you need to cite the page number of the TSpace version (original manuscript or accepted manuscript) because you cannot access the published version, then cite the TSpace version in addition to the published version using the permanent URI (handle) found on the record page. 
The company they keep: Drinking group attitudes and male bar aggression

\author{
Tara M. Dumas ${ }^{1}$ \\ Kathryn Graham $2,3,4,5$ \\ Samantha Wells $\mathrm{s}^{2,3,6}$
}

\author{
${ }^{1}$ School of Social Work, University of Illinois at Urbana-Champaign, Urbana, Illinois, US \\ ${ }^{2}$ Social and Epidemiological Research Department, Centre for Addiction and Mental Health, \\ London, Ontario, CA \\ ${ }^{3}$ Dalla Lana School of Public Health, University of Toronto, Toronto, Canada \\ ${ }^{4}$ Department of Psychology, Western University, London, Ontario, CA \\ ${ }^{5}$ National Drug Research Institute, Curtin University, Perth, AU \\ ${ }^{6}$ Department of Epidemiology, Western University, London, Ontario, CA
}

Correspondence directed to: Tara M. Dumas, Ph.D., School of Social Work, University of Illinois at Urbana-Champaign, 1010 W. Nevada Street, Urbana, IL, US, 61801, Telephone: (217)244-8351, E-mail:tdumas@illinois.edu

Research for this article was supported by a CIHR Emerging Team Grant: Co-morbidity of brain disorders and other health problems (CBG -101926) and by the Canada Foundation for Innovation (\#20289) and the Ontario Ministry of Research and Innovation.

Word count $=2,321$ 


\begin{abstract}
Aims: The aims were to assess (1) similarities in self-reported bar-aggression-related attitudes and behaviors among members of young male groups recruited on their way to bars, and (2) group-level variables associated with individual members' self-reported likelihood of perpetrating physical bar aggression in the past year, controlling for individual attitudes.

Methods: Young male natural drinking groups recruited on their way to a bar district Thursday, Friday and Saturday nights ( $n=167,53$ groups) completed an online survey that measured whether they had perpetrated physical aggression at a bar in the past year and constructs associated with bar aggression, including attitudes towards male bar aggression and frequency of heavy episodic drinking (HED) in the past year. Results: Intraclass correlations and chi-square tests demonstrated significant within-group similarity on bar aggression-related attitudes and behaviors $(p s<.01)$. Hierarchical Linear Modeling revealed that group attitudes toward bar aggression were significantly associated with individuals' likelihood of perpetrating physical bar aggression, controlling for individual attitudes $(p<.01)$; however, the link between group HED and self-reported bar aggression was nonsignificant in the full model. Conclusions: This study suggests that the most important group influence on young men's bar aggression is the attitudes of other group members. These attitudes were associated with group members' likelihood of engaging in bar aggression over and above individuals' own attitudes. A better understanding of how group attitudes and behavior affect the behavior of individual group members is needed to inform aggression prevention programming.
\end{abstract}

Keywords: Male, alcohol, drinking, bars, aggression, attitudes, peers, groups 


\section{Introduction}

Barroom aggression can lead to negative consequences for those involved, including injury and even death (Langley et al., 1996; Roche et al., 2001). Although there is increasing evidence of bar aggression by women in the UK (Forsyth \& Lennox, 2010), research elsewhere suggests that most aggression in public drinking establishments is perpetrated by young men (see Graham and Homel, 2008 for a review). Individual-level factors associated with young men's bar aggression have been identified, including normative attitudes about bar aggression (Benson and Archer, 2002; Graham and Wells, 2003; Wells et al., 2013) and heavy episodic drinking (i.e., consuming a large number of drinks on a single occasion) (HED) (Graham et al., 2006; Leonard et al., 2003; Wells et al., 2008); however, given that young adults typically attend bars in groups, it is also important to consider the possible influence of the peer group.

Peer groups are known generally to affect the behaviors of individual members (Rubin et al., 2006), through both their attitudes and behavior. For example, peer group drinking has been found to be associated with alcohol-related injuries among adolescents (Bonomo et al., 2001) and alcohol-related aggression among young men (Wells et al., 2005). In addition, young men's perceptions of their male peers' attitudes about bar aggression have been shown to be associated with their own aggressive behavior in bars (Wells et al., 2009; Wells et al., 2011); however, no studies to date have measured peer attitudes directly. Young people tend to be inaccurate in these perceptions, often overestimating peer approval for and engagement in risk behavior (Perkins, 2002 for alcohol; Vandello et al., 2009 for male aggression). Because drinking appears to be more strongly influenced by close friends rather than distant peers (Neighbors et al., 2008) and men's aggression is more strongly associated with perceived attitudes of male than female peers 
(Wells et al., 2011), it is especially important to focus on the male peers with whom young men attend bars (their natural drinking groups, NDGs; Lange et al., 2011).

In addition, individuals are likely to hold similar attitudes to those of their peers. For example, Wells and colleagues (2011) demonstrated a strong positive relationship between young men's own approval of bar aggression and their perceptions of their male peers' approval. Therefore, it is important to control for individual attitudes when assessing the role of peer attitudes in explaining bar aggression. Likewise, to assess the possible influence of peer group drinking on individual bar aggression, drinking by the individual must be controlled for, given the significant similarity in heavy episodic drinking (HED) among young adult friends (Andrews et al., 2002). Finally, in addition to assessing peer attitudes in explaining individual bar aggression, it is important to include measures of peer bar aggression. Young men believe it is important to assist their friends if they become involved in a bar conflict (Graham and Wells, 2003) and thus may become aggressive in a bar due to the aggression of someone else in their group.

In the present study, we recruited young male NDGs on their way to bars in a mid-sized Canadian city. We hypothesized that there would be significant within-NDG similarity on selfreported attitudes towards bar aggression, HED frequency, and likelihood of engaging in bar aggression. Further, we predicted that group-level attitudes towards bar aggression, HED frequency, and perpetration of physical bar aggression would be significantly associated with the likelihood that individual group members would engage in physical bar aggression in the past year, controlling for individual attitudes and behavior. 


\section{Method}

\section{Procedure}

This study was part of a larger project examining young adult bar-goers' drinking-related behavior (Dumas et al., 2014). Participants were recruited in small groups on route to the downtown bar district in a mid-sized Canadian city on weekend evenings. Eligible groups were comprised of 3-5 young adults in same sex groups who were of legal age to drink in Canada (19to-29 years of age) and residents of the community. Only male participants are included in the present analyses.

Participating groups completed a brief entry survey at recruitment, an exit survey when leaving the bar district, and an online survey in the days following recruitment. Group membership information was collected in the entry survey. Other measures are from the online survey. For more details about procedures, see Dumas et al. (2014).

\section{Participants}

Sixty-three groups of young male bar-goers $(n=218 ; M$ group size $=3.5$ members $)$ were recruited, representing $30.4 \%$ of the eligible all-male groups approached, of which $80 \%$ ( $n=$ 174) completed the online survey. Analyses were restricted to men who completed the online survey and had at least one peer also complete the survey. This reduced our final sample to 53 groups (167 men; $96 \%$ of online survey sample; $M_{\text {age }}=21.86$ years, $S D=2.52 ; 73.7 \%$ students ). The final sample of men did not differ from those excluded $(n=51)$ on age, $t(216)=-0.75, n . s$, but were significantly more likely to be students $(73.7 \%$ versus $\left.54.9 \%), \chi^{2}(1)=6.45, p=0.01\right)$. Measures

Physical Bar Aggression. Participants reported how many times in the past 12 months they grabbed, pushed, shoved, hit or kicked another person or did something else physically 
aggressive to another person at a bar. Because of the highly skewed distribution, scores were dichotomized ( 0 - no aggression and 1 - one or more instances of aggression).

Attitudes towards Bar Aggression. Participants completed the Beliefs and Attitudes toward Male Alcohol-Related Aggression Inventory - Short Form (BAMARA-SF) (Wells et al., 2013) validated by Wells et al. (2013). The scale includes 15 statements reflecting attitudes towards male-to-male physical aggression at bars rated on a 5-point Likert scale (strongly agree to strongly disagree) with higher scores indicating greater approval. Example items are as follows: "Fighting is a normal part of going to bars", "Guys are cowards if they back down from a fight at a bar", "I'd feel pretty bad about myself the next day if I got into a fight at a bar", and "Sometimes it's exciting to be part of a bar fight." Internal consistency was good $(\alpha=.87)$.

Heavy Episodic Drinking. Participants were given a definition of a Canadian standard drink - 341-ml. (12 oz.) of beer, $142 \mathrm{ml}$. (5 oz.) of wine, $43 \mathrm{ml}$. (1.5 oz.) of liquor, or 341-ml. (12 oz.) of a premixed drink - and shown illustrative examples. They recorded how many times on a single occasion in the past 12 months they consumed: (1) 8-to-11 drinks, and (2) 12-or-more drinks. HED was calculated as the sum of items 1 and 2. We chose a cut-off of 8-or-more drinks because naturalistic research (Lange and Voas, 2001) suggests that this level of consumption is associated with reaching a blood alcohol level (BAC) of .08, an accepted threshold for defining HED (Beirness, Foss, \& Vogel-Sprott, 2005). Further, research suggests that a higher cut-off than the more commonly used 5-or-more drinks is more predictive of men's negative drinkingrelated consequences (Jackson, 2008; O'Malley and Johnston, 2002).

Peer group bar aggression, attitudes and HED. Peer group aggression was defined as whether anyone in the participant's NDG, other than himself, reported engaging in physical aggression at a bar in the last 12 months $(1=$ one or more group member reported bar 
aggression, 0 = no group members reported aggression). Other peer group measures included BAMARA scores and HED scores averaged across all group members excluding that participant to avoid confounding the group measure with the individual's own score.

Analysis

We used the software program HLM 6.0 to run our main analyses. To test group member similarity on bar aggression-related variables, we derived intraclass correlations (ICCs) which measure the proportion of variance in a given variable that is found between versus within groups and is thus attributable to group membership. To test whether group scores were significantly associated with individual participants' self-reported bar aggression, we used Hierarchical Linear Modeling (HLM) (Bryk and Raudenbush, 1992). HLM accounted for the multi-level structure of the data - individuals (level-1) nested within groups (level-2). Given that physical bar aggression was dichotomous, we used the Bernoulli option for dichotomous outcomes with Laplace approximation.

We first examined the unadjusted associations (i.e., bivariate relationships) between each variable and physical bar aggression. Second, we tested three models to examine associations with: (1) individual variables (HED, BAMARA, and age), (2) group variables (peer HED, BAMARA, and bar aggression), and (3) group variables when controlling for individual variables. Group variables were entered at level-1 rather than level-2 because each participant had a different set of peers and thus different scores on each measure. All independent variables were grand-mean centered for ease of interpretation.

\section{Results}

Eighteen percent $(n=30)$ of participants reported perpetrating physical bar aggression in the past year and 32.9\% $(n=55)$ had at least one other group member who reported aggression. 
Significant $(p<.05)$ zero-order inter-correlations were found among most variables $(r=0.20$ to 0.36), with the exception of individual HED with peer BAMARA $(r=0.15)$, and peer HED with individual BAMARA $(r=0.12)$. Descriptive tables are available upon request.

Consistent with hypotheses, ICCs were significant with $20 \%$ of the variance in BAMARA scores $\left(\chi^{2}=92.96, p<.01\right)$ and $29 \%$ of the variance in $\operatorname{HED}\left(\chi^{2}=107.25 p<.001\right)$ attributed to group membership. Also, a significantly larger proportion of participants who engaged in physical bar aggression (versus those who had not) had one or more group members who also engaged in bar aggression in the past year $\left(50 \%\right.$ versus $\left.29.2 \% ; \chi^{2}(1)=4.82, p=.028\right)$.

Table 1 illustrates HLM results. As shown in Model 1, although the unadjusted coefficients showed that both the BAMARA and HED were significantly related to bar aggression at the individual level, only the BAMARA remained significant when both were in the same model. For group variables, average group BAMARA scores and bar aggression by others in the group were significantly associated with the individual's bar aggression in the unadjusted model; however, as shown in Model 2, only group BAMARA scores remained significant when all group variables were in the model, and this significant relationship was maintained when individual variables were included in the model (Model 3).

Insert Table 1 about here

\section{Discussion}

As hypothesized, we found significant similarities among NDG members in attitudes, HED, and experiences of physical bar aggression, consistent with previous research on HED (Andrews, et al., 2002) and perceived peer approval of bar aggression (Wells, et al., 2011). These 
findings are concerning because NDGs with shared positive attitudes toward bar aggression may be particularly attracted to settings that are conducive to or tolerant of aggressive behavior, thereby increasing risk of injury to themselves and others.

Also, consistent with hypotheses, we found that NDG attitudes were significantly related to individual group members' self-reported likelihood of experiencing physical bar aggression, and this relationship remained significant after controlling for individual attitudes. Thus, even though peer groups may indirectly affect members' behavior by socializing individual attitudes (e.g., Prinstein and Dodge, 2008), our results suggest that group attitudes also appear to have a direct link with members' behavior in the bar context. These results are particularly noteworthy because they empirically quantify and validate that young men's behaviors in the bar are related to the actual attitudes of other peer group members, whereas past research has measured perceived attitudes of peers (Wells et al., 2011). Further, we found that group attitudes were more strongly related to young men's self-reported bar aggression than was actual bar aggression by others in the group. Thus, when it comes to physical bar aggression, perhaps what peers think and say is more influential than what they actually do, possibly because bar aggression is too infrequent to be modeled by peers unlike peer modeling of drinking (O'Grady et al., 2011; van Schoor et al., 2008).

Contrary to prediction, group HED was not significantly associated with self-reported bar aggression. Thus, previous findings of a positive link between number of alcohol-consuming peers and young men's verbal or physical aggression at a bar (Wells et al., 2005) may reflect greater bar attendance and HED among men who have more drinking peers, which may, in turn, put them at increased risk for bar aggression. In contrast, we focused on groups of bar-goers, who may not vary greatly in high risk drinking-related activities such as going to bars. In 
addition, it is possible that an assessment of group intoxication at the bar that night would be a more appropriate predictor of individual members' likelihood of engaging in physical bar as compared to the frequency with which group members engage in HED in general.

\section{Limitations}

Several limitations should be noted. First, the data are cross-sectional and longitudinal research is necessary to disentangle directional effects. Second, participants were not necessarily with the same group when they perpetrated bar aggression as they were on the night of recruitment. Stronger associations might have been obtained had peer measures been collected from the participant's companions on the night of aggression; however, this makes the associations between peer attitudes and individual aggression in the present study even more noteworthy. Third, we relied on an all-male sample because young men are involved in the majority of physical bar aggression (Graham and Homel, 2008); it would be informative to include female participants in subsequent research on group contributions to risk behaviors at the bar. Fourth, due to our response rate and sample size we must be cautious when generalizing results. Finally, the sample of participants reporting aggression was fairly small and thus we treated this variable as dichotomous. A larger sample size with more variability in perpetration of physical bar aggression is needed to examine the relation between NDG attitudes and members' frequency of bar aggression.

To conclude, given the strength of associations of self-reported individual aggression with individual and group attitudes toward bar aggression, the current findings suggest that challenging positive attitudes towards bar aggression held by young men may be a critical direction for prevention programming. 


\section{References}

Andrews, J. A., Tildesley, E., Hops, H., \& Li, F. (2002). The influence of peers on young adult substance use. Health Psychology, 21(4), 349-357.

Beirness, D. J., Foss, R. D., \& Vogel-Sprott, M. (2004). Drinking on campus: self-reports and breath tests. Journal of Studies on Alcohol and Drugs, 65(5), 600.

Benson, D., \& Archer, J. (2002). An ethnographic study of sources of conflict between young men in the context of the night out. Psychology, Evolution \& Gender, 4(1), 3-30. doi: $10.1080 / 1461666021000013742$

Bonomo, Y., Coffey, C., Wolfe, R., Lynskey, M., Bowes, G., \& Patton, G. (2001). Adverse outcomes of alcohol use in adolescents. Addiction, 96, 1485-1496. doi: 10.1046/j.13600443.2001.9610148512.x

Bryk, A., \& Raudenbush, S. W. (1992). Hierarchical linear models. Newbury Park, CA: Sage.

Bushman, B. J. (1997). Effects of alcohol on human aggression: Validity of proposed explanations. In M. Galanter (Ed.), Recent Developments in Alcoholism (Vol. 13, pp. 227-243). New York: Plenum Press.

Dumas, T. M., Wells, S., Flynn, A., Lange, J., \& Graham, K. (2014). The influence of status on group drinking by young adults: A survey of natural drinking groups on their way to and from bars. Alcoholism: Clinical and Experimental Research, 38(4), 1100-1107. doi: 10.1111/acer.12314

Ellis, W. E., \& Zarbatany, L. (2007). Peer group status as a moderator of group influence on children's deviant, aggressive, and prosocial behavior. Child Development, 78(4), 12401254. 
Espelage, D. L., Holt, M. K., \& Henkel, R. R. (2003). Examination of Peer-Group contextual effects on aggression during early adolescence. Child Development, 74(1), 205-220.

Forsyth, A. J.M., \& Lennox, J. C. (2010). Gender differences in the choreography of alcoholrelated violence: An observational study of aggression within licensed premises. Journal of Substance Use, 15, 75-88.

Giancola, P. R. (2002). Alcohol-related aggression during the college years: Theories, risk factors and policy implications. Journal of Studies on Alcohol, 14(Suppl.), 129-139.

Graham, K., \& Homel, R. (2008). Raising the bar: Preventing aggression in and around bars, pubs and clubs. Oxford, UK: Routledge Publishing (Taylor \& Francis group).

Graham, K., Osgood, D. W., Wells, S., \& Stockwell, T. (2006). To what extent is intoxication associated with aggression in bars? A multilevel analysis. Journal of Studies on Alcohol, 67(3), 382-390.

Graham, K., \& Wells, S. (2003). "Somebody's gonna get their head kicked in tonight!" Aggression among young males in bars -- A question of values? British Journal of Criminology, 43, 546-566. doi: 10.1093/bjc/43.3.546

Jackson, K. M. (2008). Heavy episodic drinking: Determining the predictive utility of five or more drinks. Psychology of Addictive Behaviors, 22(1), 68-77. doi: 10.1037/0893164X.22.1.68

Langley, J., Chalmers, D., \& Fanslow, J. (1996). Incidence of death and hospitalization from assault occurring in and around licensed premises: A comparative analysis. Addiction, 91(7), 985-993. doi: 10.1046/j.1360-0443.1996.9179855.x 
Leonard, K. E., Collins, R. L., \& Quigley, B. M. (2003). Alcohol consumption and the occurrence and severity of aggression: An event-based analysis of male to male barroom violence. Aggressive Behavior, 29, 346-365. doi: 10.1002/ab.10075

Lipsey, M. W., Wilson, D. B., Cohen, M. A., \& Derzon, J. H. (1997). Is there a causal relationship between alcohol use and violence? A synthesis of evidence. Recent Developments in Alcoholism, 13, 245-282. doi: 10.1007/0-306-47141-8_14

Macdonald, S., Wells, S., Giesbrecht, N., \& Cherpitel, C. J. (1999). Demographic and substance use factors related to violent and accidental injuries: Results from an emergency room study. Drug and Alcohol Dependence, 55, 53-61. doi: 10.1016/S0376-8716(98)00184-7

Neighbors, C., Dillard, A. J., Lewis, M. A., Bergstrom, R. L., \& Neil, T. A. (2006). Normative misperceptions and temporal precedence of perceived norms and drinking. Journal of Studies on Alcohol, 67, 290-299.

Neighbors, C., O’Conner, R. M., Lewis, M. A., Chawla, N., Lee, C. M., \& Fossos, N. (2008). The relative impact of injunctive norms on college student drinking: The role of reference group. Psychology of Addictive Behaviors, 22, 576-581. doi: 10.1037/a0013043

O'Malley, P. M., \& Johnston, L. D. (2002). Epidemiology of alcohol and other drug use among American college students. Journal of Studies on Alcohol, 14(suppl), 23-39.

O’Grady, M. A., Cullum, J., Tennen, H., \& Armell, S. (2011). Daily relationship between eventspecific drinking norms and alcohol use: A four-year longitudinal study. Journal of Studies on Alcohol and Drugs, 72, 633-641.

Perkins, H. W. (2002). Social norms and the prevention of alcohol misuse in collegiate contexts. Journal of Studies on Alcohol, 14(Suppl), 164-172. 
Prinstein, M. J., \& Dodge, K. A. (Eds.). (2008). Understanding peer influence in children and adolescents. New York, NY: Guilford Press.

Roche, A. M., Watt, K., McClure, R., Purdie, D. M., \& Green, D. (2001). Injury and alcohol: A hospital emergency department study. Drug and Alcohol Review, 20, 155-166. doi: $10.1080 / 09595230120058542$

Rubin, K. H., Bukowski, W. M., \& Parker, J. G. (2006). Peer interactions, relationships, and groups. In N. Eisenberg, D. William \& R. M. Lerner (Eds.), Handbook of child psychology: Social, emotional, and personality development (6th ed., Vol. 3, pp. 571645). Hoboken, NJ: John Wiley \& Sons Inc.

Shi, B., \& Xie, H. (2012). Socialization of physical and social aggression in early adolescents' peer groups: High-status peers, individual status, and gender. Social Development, 21, 170-194.

Tomsen, S. (1997). A top night out -- Social protest, masculinity and the culture of drinking violence. British Journal of Criminology, 37, 990-1002.

Tuck, M. (1989). Drinking and disorder: A study of non-Metropolitan violence (Home office research study \#108 ed., pp. 11-103). London, England: Her Majesty's Stationery Office.

Urberg, K. A., Değirmencioğlu, S. M., \& Pilgrim, C. (1997). Close friend and group influence on adolescent cigarette smoking and alcohol use. Developmental Psychology, 33(5), 834844.

van Schoor, G., Bot, S. M., \& Engels, R. C. M. E. (2008). Alcohol drinking in young adults: The predictive value of personality when peers come around. European Addiction Research, 14, 125-133. doi: 10.1159/000130416 
Vandello, J. A., Ransom, S., Hettinger, V. E., \& Askew, K. (2009). Men's misperceptions about the acceptability and attractiveness of aggression. Journal of Experimental Social Psychology, 45(6), 1209-1219.

Voas, R. B., Furr-Holden, D., Lauer, E., Bright, K., Johnson, M. B., \& Miller, B. (2006). Portal surveys of time-out drinking locations. A tool for studying binge drinking and AOD use. Evaluation Review, 30(1), 44-65. doi: 10.1177/0193841X05277285

Wechsler, H., \& Nelson, T. F. (2001). Binge drinking and the American college student: What's five drinks. Psychology of Addictive Behaviors, 15, 287-291. doi: 10.1037/0893164X.15.4.287

Wells, S., Graham, K., Speechley, M., \& Koval, J. (2005). Drinking patterns, drinking contexts, and alcohol-related aggression among late adolescent and young adult drinkers. Addiction, 100, 933-944. doi: 10.1111/j.1360-0443.2005.001121.x

Wells, S., Graham, K., \& Tremblay, P. F. (2009). "Every male in there is your competition": Young men's perceptions regarding the role of the drinking setting in male-to-male barroom aggression. Substance Use \& Misuse, 44(9), 1434-1462. doi:

$10.1080 / 10826080902961708$

Wells, S., Mihic, L., Tremblay, P. F., Graham, K., \& Demers, A. (2008). Where, with whom, and how much alcohol is consumed on drinking events involving aggression? Event-level associations in a Canadian national survey of university students. Alcoholism: Clinical and Experimental Research, 32(3), 1-12. doi: 10.1111/j.1530-0277.2007.00596.x

Wells, S., Neighbors, C., Tremblay, P. F., \& Graham, K. (2011). Defending girlfriends, buddies, and oneself: Injunctive norms and male barroom aggression. Addictive Behaviors, 36, 416-420. doi: 10.1016/j.addbeh.2010.12.006 
Wells, S., Tremblay, P. F., \& Graham, K. (2013). Understanding men's aggression in bars: Development of the Beliefs and Attitudes toward Male Alcohol-Related Aggression (BAMARA) Inventory. Alcoholism: Clinical and Experimental Research, 37, e260-e270. 
Table 1. Hierarchical Linear Models Predicting Physical Bar Aggression in the Past Year from Individual and Peer BAMARA and HED Scores and Peer Bar Aggression

\begin{tabular}{|c|c|c|c|c|c|c|c|c|c|c|c|c|}
\hline \multirow[b]{3}{*}{ Predictors } & \multirow{2}{*}{\multicolumn{3}{|c|}{ Unadjusted associations }} & \multicolumn{3}{|c|}{ Model 1} & \multicolumn{3}{|c|}{ Model 2} & \multicolumn{3}{|c|}{ Model 3} \\
\hline & & & & \multicolumn{3}{|c|}{ Individual level effects } & \multicolumn{3}{|c|}{ Group level effects } & \multicolumn{3}{|c|}{ Individual and group level effects } \\
\hline & $\mathrm{b}(\mathrm{SE})$ & OR & $95 \% \mathrm{CI}$ & $\mathrm{b}(\mathrm{SE})$ & OR & $95 \% \mathrm{CI}$ & $\mathrm{b}(\mathrm{SE})$ & OR & $95 \% \mathrm{CI}$ & $\mathrm{b}(\mathrm{SE})$ & OR & $95 \% \mathrm{CI}$ \\
\hline \multicolumn{13}{|l|}{ Individual Variables } \\
\hline BAMARA & $1.32(0.36)^{* * *}$ & 3.72 & $1.82,762$ & $1.56(0.49)^{* *}$ & 4.77 & $1.81,12.59$ & & & & $1.55(0.53)^{* *}$ & 4.71 & $1.90,11.72$ \\
\hline HED & $0.02(0.01)^{*}$ & 1.02 & $1.00,1.03$ & $0.01(0.01)$ & 1.01 & $1.00,1.03$ & & & & $0.01(0.01)$ & 1.01 & $0.99,1.03$ \\
\hline Age & $-0.07(0.09)$ & 0.93 & $0.78,1.12$ & $0.03(0.11)$ & 1.03 & $0.84,1.28$ & & & & $0.07(0.10)$ & 1.08 & $0.88,1.32$ \\
\hline \multicolumn{13}{|l|}{ Group Variables } \\
\hline Group BAMARA & $1.11(0.24)^{* *}$ & 3.02 & $1.33,6.87$ & & & & $1.29(0.52)^{*}$ & 3.65 & $1.32,10.09$ & $1.55(0.65)^{*}$ & 4.71 & $1.31,16.33$ \\
\hline Group HED & $-0.00(0.02)$ & 1.00 & $0.98,1.02$ & & & & $-0.01(0.02)$ & 0.99 & $0.96,1.02$ & $-0.02(0.02)$ & 0.98 & $0.95,1.02$ \\
\hline Group Bar & $0.85(0.41)^{*}$ & 2.33 & $1.03,5.26$ & & & & $0.30(0.52)$ & 1.35 & $0.48,3.80$ & $-0.82(0.68)$ & 0.44 & $0.11,1.70$ \\
\hline Aggression & & & & & & & & & & & & \\
\hline
\end{tabular}

